\title{
An effective zinc-substituted Keggin composite to catalyze the removal of sulfur from real diesels under solvent-free system
}

Susana O. Ribeiro, ${ }^{a}$ Carlos M. Granadeiro, ${ }^{a^{*}}$ Pedro L. Almeida, ${ }^{b}$ João Pires, ${ }^{c}$ Rita Valença, ${ }^{d}$ José M. Campos-Martin, ${ }^{e}$ Jorge C. Ribeiro, ${ }^{d}$ Baltazar de Castro ${ }^{a}$ and Salete S. Balula $\mathrm{a}^{*}$

a LAQV-REQUIMTE, Departamento de Química e Bioquímica, Faculdade de Ciências, Universidade do Porto, 4169-007 Porto, Portugal

${ }^{b}$ CENIMAT/I3N, Faculdade de Ciências e Tecnologia, Universidade Nova de Lisboa, 2829-516 Monte da Caparica, and AD Física, ISEL/IPL, R. Conselheiro Emídio Navarro, 1, 1959-007 Lisboa, Portugal

c Centro de Química e Bioquímica and CQE, Faculdade de Ciências, Universidade de Lisboa, 1749-016 Lisboa, Portugal

d Galp, Refinaria de Matosinhos, 4452-852 Leça da Palmeira, Matosinhos, Portugal

e Grupo de Energía y Química Sostenibles (EQS), Instituto de Catálisis y Petroleoquímica, CSIC, Marie Curie, 2 Canto Blanco, Madrid, Spain

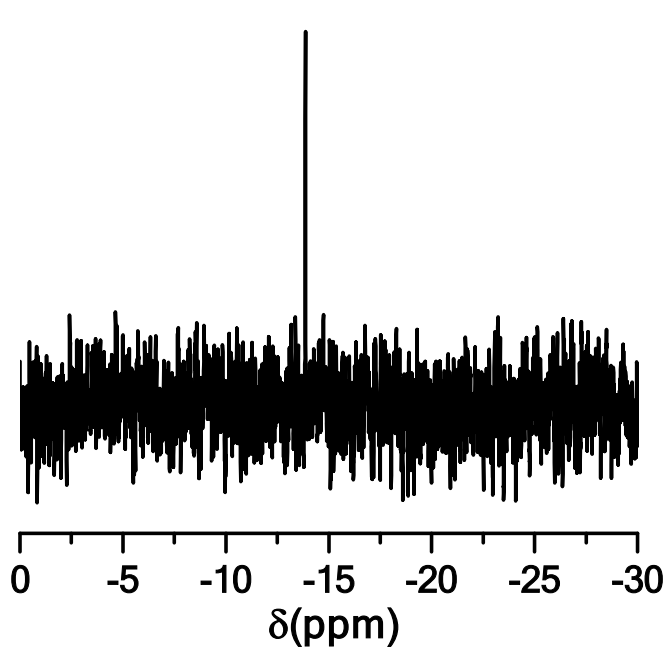

Figure S1. ${ }^{31} \mathrm{P}$ NMR spectra of the MeCN phase of the leaching test using the $\mathrm{PW}_{12} @$ aptesSBA15 catalyst. 


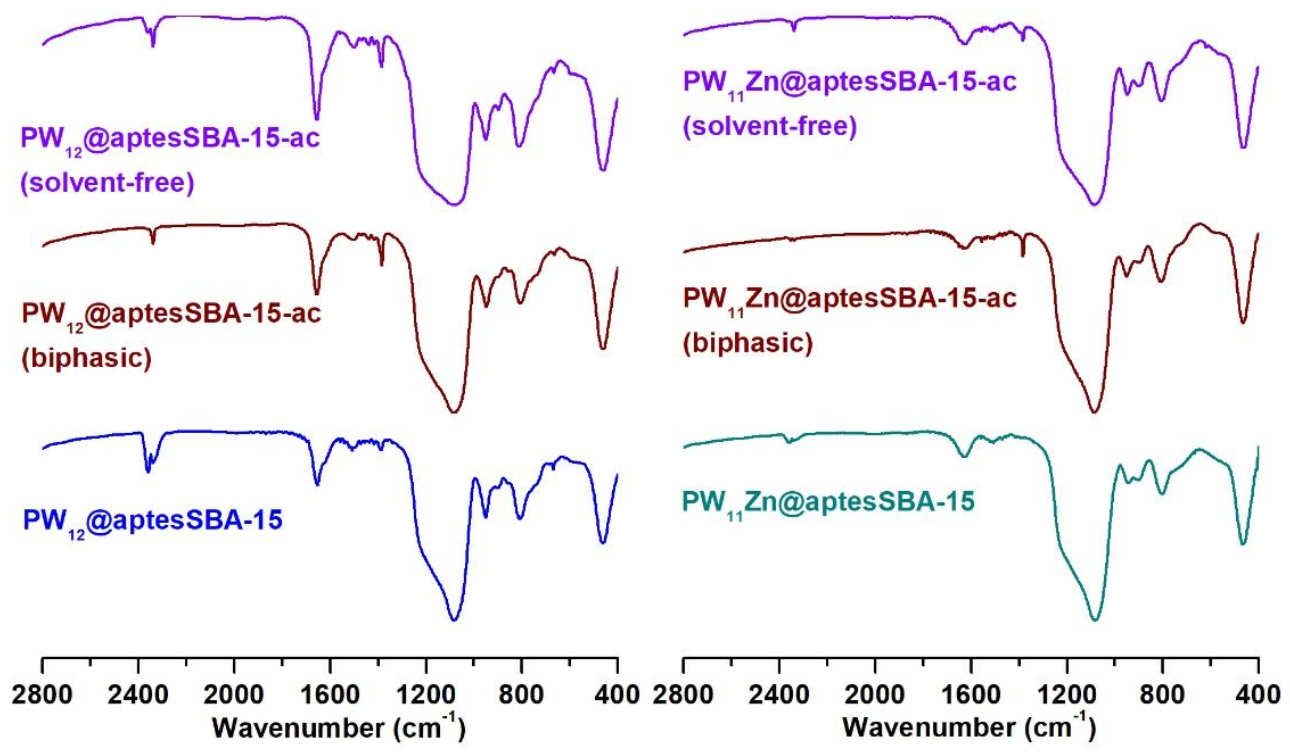

Figure S2. FT-IR spectra of the PW ${ }_{12} @$ aptesSBA-15 and PW 11 Zn@aptesSBA-15 composites before and after catalytic use (ac is the abbreviation for after catalysis). 

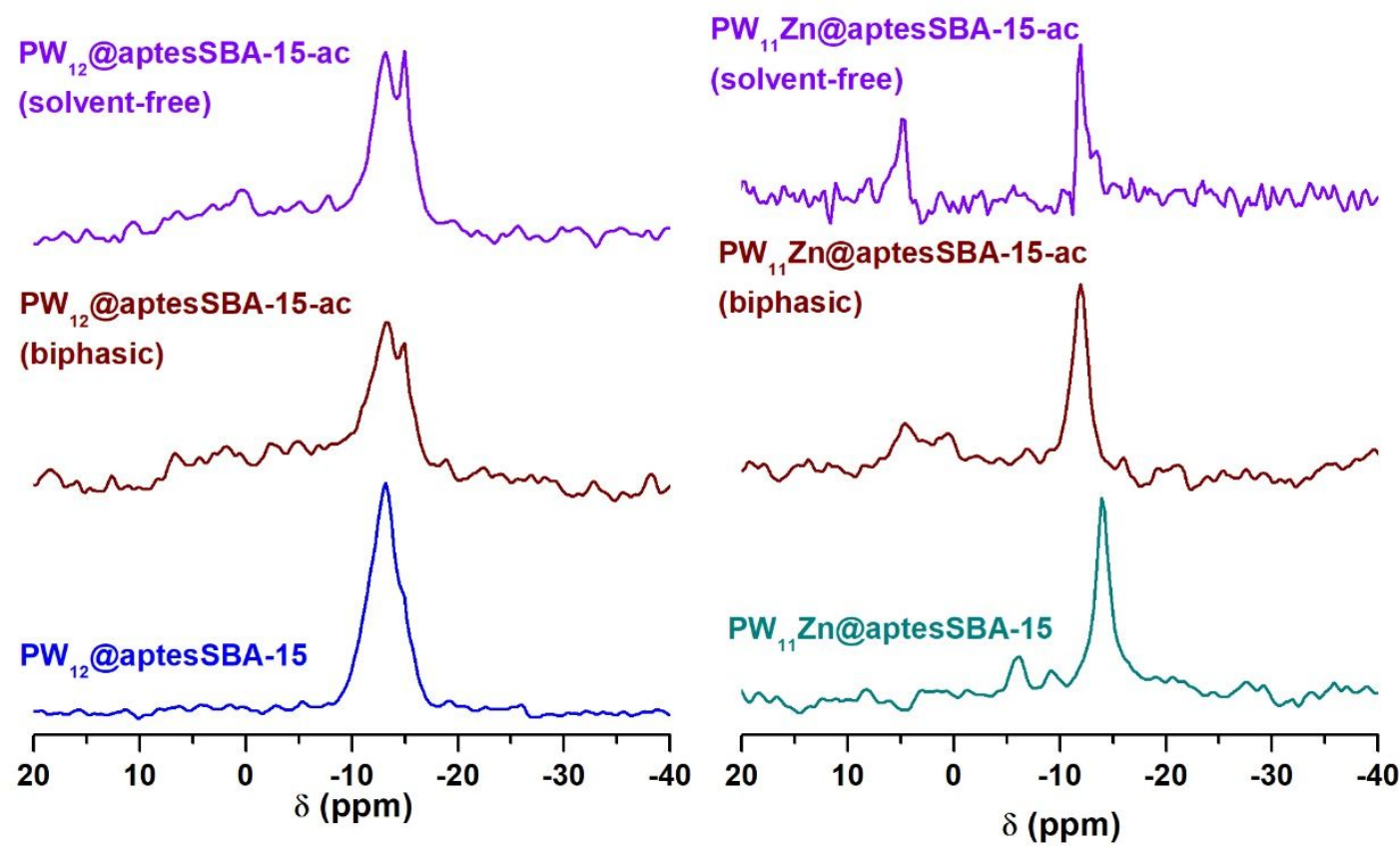

Figure S3. ${ }^{31} \mathrm{P}$ MAS NMR spectra of the PW $12 @$ aptesSBA-15 and PW ${ }_{11} Z n @ a p t e s S B A-15$ composites before and after catalytic use (ac stands for after catalysis).

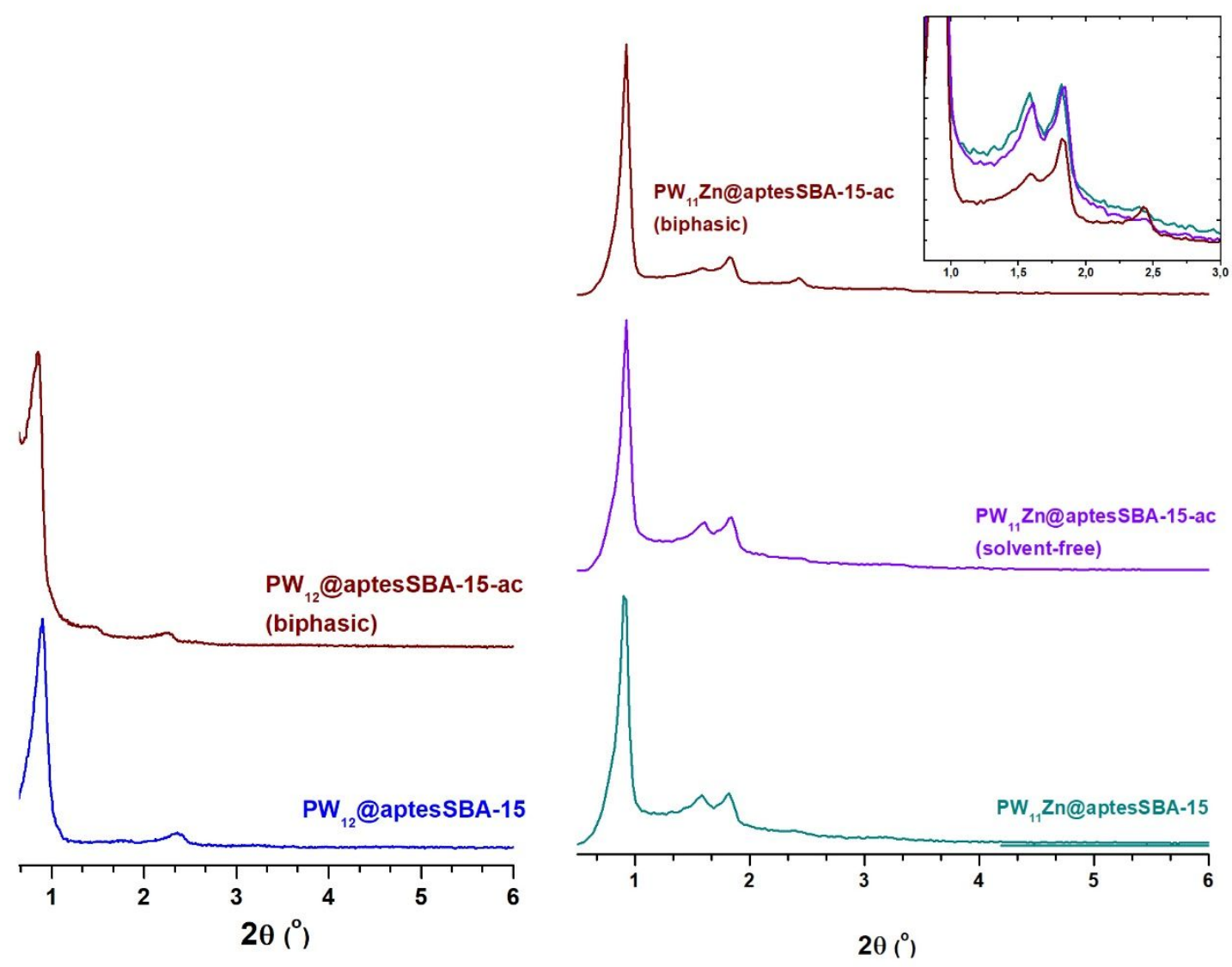


Figure S4. Powder XRD patterns of the composites PW $11 \mathrm{Zn@aptesSBA-15}$ and PW $12 @$ aptesSBA-15 before and after catalytic use (ac is the abbreviation for after catalysis).
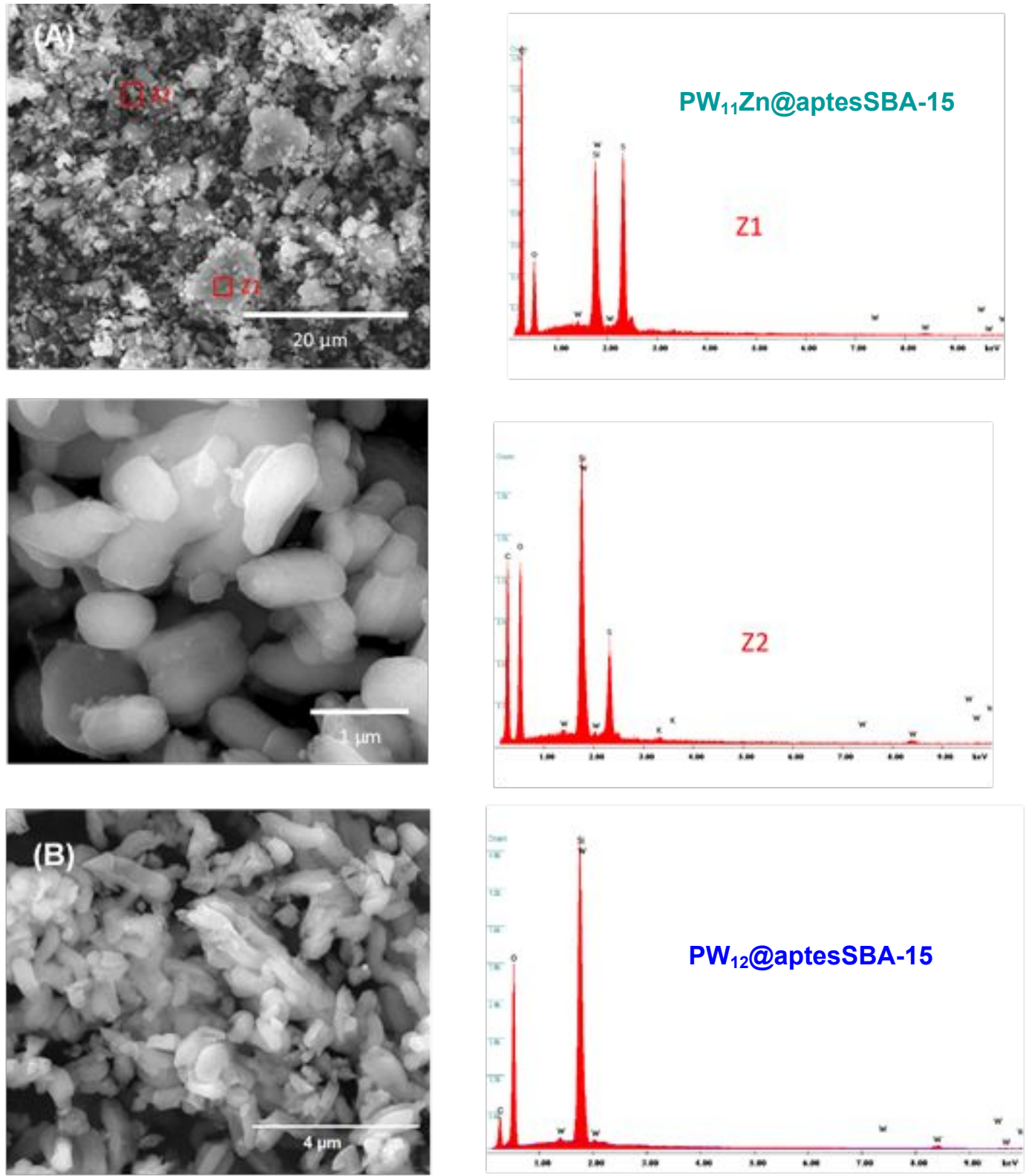

Figure S5. SEM images and EDS spectra of (A) PW 11 Zn@aptesSBA-15 after ten cycles under the solvent-free system and (B) PW $12 @$ aptesSBA-15 after one cycle under the biphasic system. 


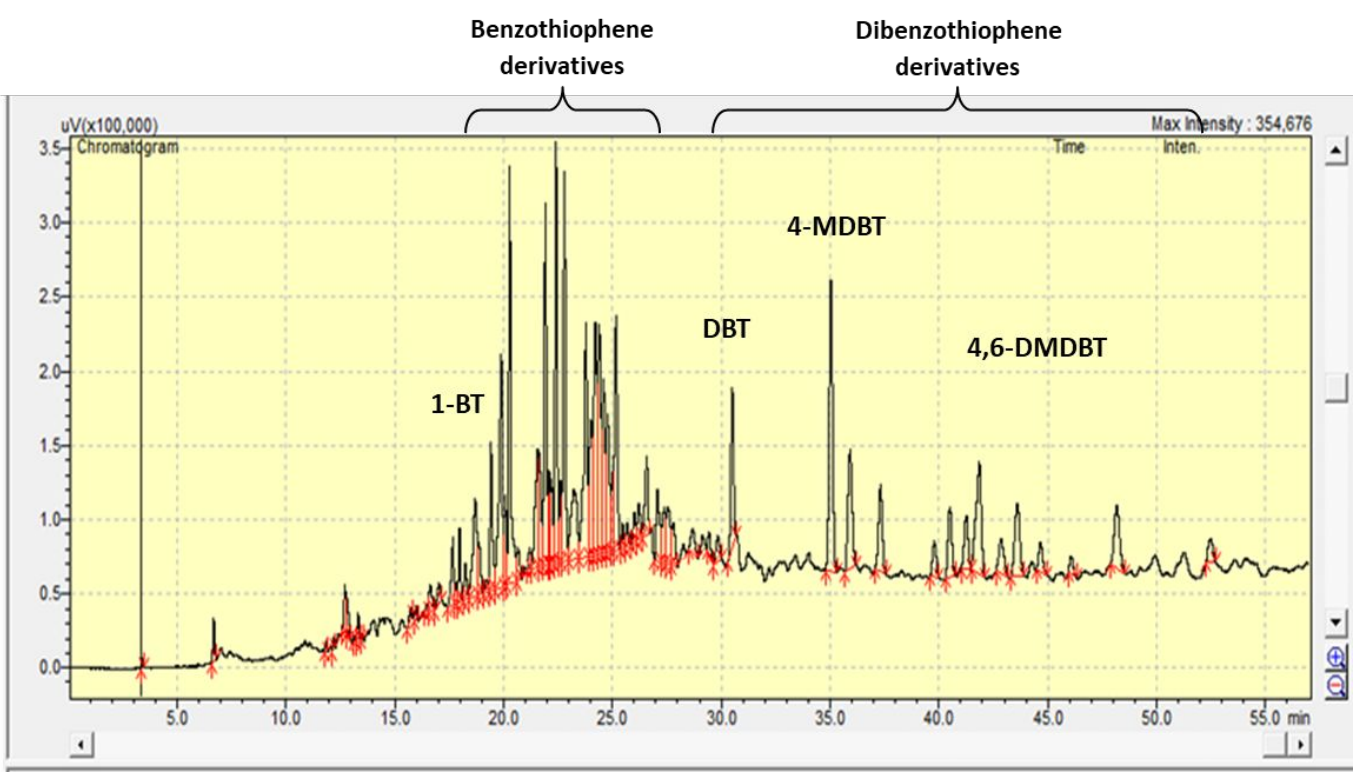

Figure S6. Chromatogram (GC-FPD) of untreated GALP diesel.

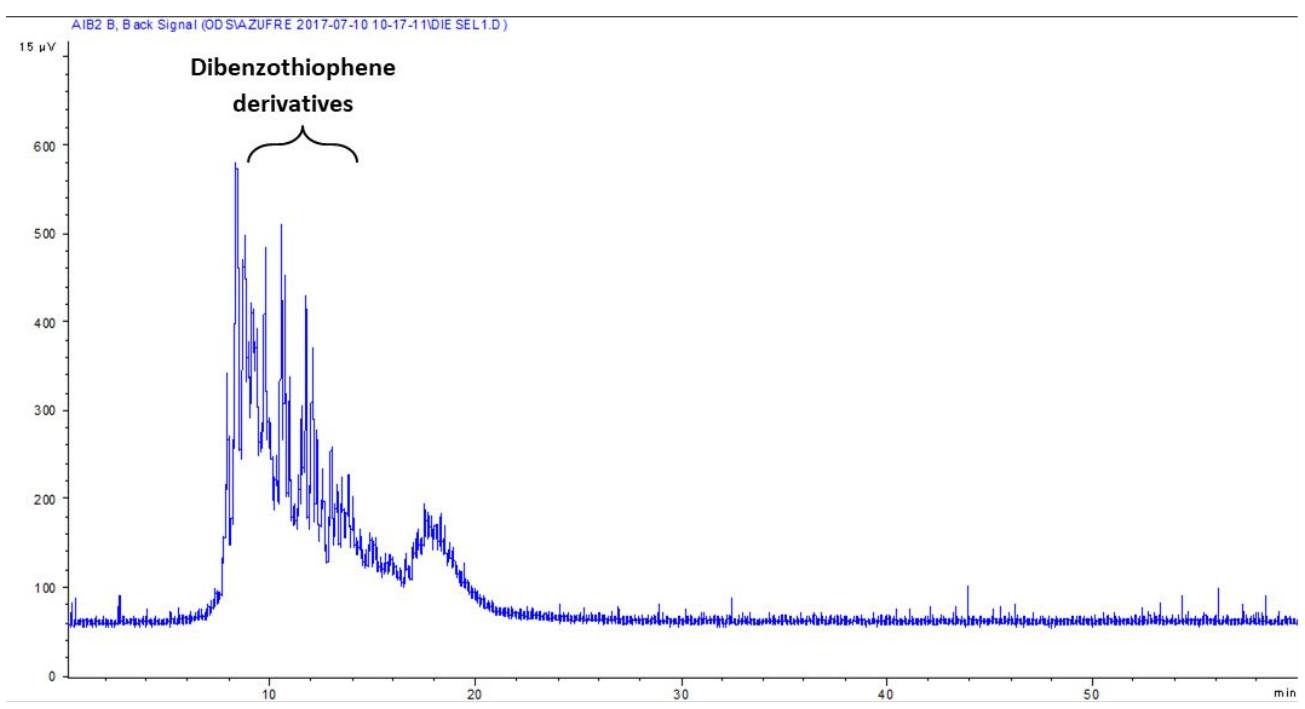

Figure S7. Chromatogram (GC-FPD) of untreated CEPSA diesel. 